\title{
Décès de M. V. H. Umbricht membre honoraire du CICR
}

C'est avec une très grande émotion que le CICR a appris le décès, survenu le 14 juillet 1988 , à la suite d'une très longue maladie, de M. Victor H. Umbricht, membre honoraire du CICR, ancien Viceprésident du CICR.

Depuis près de vingt ans, Victor $H$. Umbricht, membre depuis 1970 , membre et Vice-président du Conseil exécutif depuis 1973, puis Viceprésident du Comité international de la Croix-Rouge jusqu'en 1985, membre honoraire depuis 1986, a marqué de sa personnalité et de ses réalisations les profondes mutations de l'institution qui était aussi la sienne.

Né à Endingen (Suisse) en 1915, docteur en droit international de l'Université de Berne, M. Umbricht fut de 1941 à 1953 au service diplomatique de la Suisse. Appelé en tant que Directeur adjoint des opérations pour l'Europe, l'Afrique, l'Asie et l'Australasie, à la Banque Mondiale à Washington, il fut nommé en 1957 Directeur de l'Administration fédérale des finances à Berne. De 1960 à 1961, il fut Conseiller financier et président du Conseil monétaire à Kinshasa (Zaire), puis de 1965 à 1985 membre du Conseil d'administration de la Société CIBA et de CIBA-GEIGY à Bâle. Il fut également de 1968 à 1976 membre du Conseil consultatif du Comité du Mékong (Organisation économique pour le développement économique du bassin du Mékong, comprenant le Cambodge, le Laos, la Thaillande et le Viet Nam), sous les auspices de l'ONU.

Pour le compte du CICR, il a participé à de nombreuses missions dans les foyers de crise les plus difficiles du monde: au Proche-Orient pendant la guerre d'octobre 1973, en Asie du Sud-est pendant les guerres du Vietnam et du Cambodge, au Bangladesh pendant la guerre d'indépendance et en Ouganda pendant les sanglantes émeutes internes. 
Médiateur des Nations Unies pour la communauté de l'Afrique de l'Est de 1977 à 1984, il réussit à régler le différend qui opposait le Kenya, l'Ouganda et la Tanzanie. Ce succès lui valut l'estime générale des parties en cause.

Les exceptionnelles capacités de Victor Umbricht comme médiateur et intermédiaire international ont d'ailleurs bénéficié au Mouvement de la Croix-Rouge et à son objectif spécifique d'aide et de protection des victimes de guerres, et donc aux milliers d'hommes et de femmes pour lesquels il est inlassablement intervenu dans le monde entier.

En rendant hommage à la mémoire de Victor $\mathrm{H}$. Umbricht, le Président du CICR, M. Cornelio Sommaruga, a déclaré: «Victor Umbricht s'est consacré à la cause de la Croix-Rouge avec un optimisme inébranlable, une énergie inflexible et un dévouement inlassable... Véritable citoyen du monde, Victor Umbricht ne se contentait pas d'être un simple membre. Il s'identifiait totalement aux objectifs du CICR et voulait donc aussi que notre institution fût fidèle à ses propres principes de compétence absolue, de non-formalisme, de modestie discrète et de tolérance sans paternalisme... Ses objectifs et ses souhaits demeurent les nôtres. Nous lui sommes profondément redevables de nous avoir servi d'exemple,... et nous nous sommes imprégnés de son modèle».

\section{Décès du professeur D. Frei membre du CICR}

Le $1^{\text {er }}$ août 1988 est subitement décédé le professeur Daniel Frei, membre du Comité international de la Croix-Rouge depuis le $1^{\text {er }}$ mars 1986.

Né le 24 octobre 1940 à Saint-Gall, Daniel Frei a reçu son doctorat en histoire à l'Université de Zurich à l'âge de 24 ans. Il a poursuivi ses études à la «London School of Economics and Political Science», puis à l'Université de Michigan et a obtenu, en 1967, un diplôme à l'Institut universitaire de hautes études internationales à Genève.

Dès 1968, il était privat-docent, puis dès 1971, professeur ordinaire de sciences politiques à l'Université de Zurich. Il y dirigeait également l'Institut suisse de recherches internationales. 